\title{
O olho que não lê, agora pode ver: Menino de Engenho para as massas sob a ótica do cinema novo: deslocamentos e transposições
}

Maria Margareth Vieira Pacheco Rodrigues, Superintendência de Documentação, Universidade Federal Fluminense, Niterói, RJ; E-mail: <quintamaria@gmail.com>.

Juliana Godinho Eccard, Instituto Federal de Educação Ciência e Tecnologia Fluminense, Campos dos Goytacazes, RJ; E-mail: <julianaeccard@hotmail.com>.

\section{Resumo}

Propõe uma análise comparativa entre $o$ romance Menino de engenho de José Lins do Rego com a adaptação cinematográfica de Walter Lima Jr que recebeu o mesmo título. Relaciona o romance de José Lins do Rego com o paralelo traçado entre memória, cultura e literatura. Contextualiza o leitor acerca da criação da nova mídia denominada cinema e explica qual a proposta dos cineastas que apostaram na produção para o Cinema Novo. Coteja as abordagens adotadas na produção para as massas que seriam deslocamentos e transposições comparados à obra literária

Palavras-chave: Cinema novo, Cultura de massa, Cultura regional, Intersemiótica, Literatura, Memória.

\section{Introdução}

O presente artigo apresenta uma breve análise da tradução intersemiótica da Literatura para o Cinema, a partir da obra Menino de engenho, do ponto de vista dos deslocamentos e transposições sob a ótica do Cinema Novo.

Para alcançar o objetivo proposto, empregou-se como metodologia a análise comparativa e, para tanto, fez-se uma leitura minuciosa do livro e em seguida, assistiu-se ao filme. A partir dessas apreciações destacaram-se as abordagens representadas.

O referencial teórico foi embasado em alguns autores que tratam a Literatura em relação à Memória e a Cultura dentro do 
contexto proposto no âmbito das culturas popular, erudita e de massa. Assim o estudo fundamentou-se, e a partir da leitura isolaram-se as categorias, as ideias que se mostraram fundamentais para formar a construção planejada.

\section{Literatura e memória: representação da cultura}

Da oralidade à Galáxia de Gutemberg ${ }^{1}$ (Mcluhan, 1969) a literatura circula pelos séculos, sempre acompanhada da memória. Sem memória talvez não existisse literatura.

Silva (2005) comenta que "a literatura encontrou no texto impresso o vetor que potenciou com relativa segurança e fidedignidade a sua capacidade comunicativa, quer no tempo, quer no espaço".

A literatura, portanto, enquanto representação age como fonte de significados e suscita a abordagem dos aspectos culturais da sociedade a que se refere. A partir dessa abordagem, a representação literária legitima aspectos da cultura regional e imprime a identidade do grupo.

Ao lermos as obras dos romancistas da década de trinta, percebemos que a memória é a principal matéria utilizada na construção de suas produções. Albuquerque (2011) ressalta

\footnotetext{
${ }^{1}$ A Galáxia de Gutenberg é uma obra de Marshall McLuhan, na qual este analisa a emergência da escrita e da tipografia. A tecnologia tipográfica que nasce com Gutenberg é fundadora da modernidade e da civilização industrial. Num primeiro momento, com a escrita, há uma transição da cultura tribal, fechada e estável para o aparecimento do homem alfabetizado, individualizado, vivendo na instabilidade das sociedades modernas. Num segundo momento, com o advento da tipografia, intensifica-se o culto do indivíduo, a ideia de nação. Segundo McLuhan, nacionalismo, industrialização e mercados de massa são resultado da extensão tipográfica do homem.
} 
que o movimento regionalista tradicionalista, através de suas narrativas memorialísticas, tenta recuperar manifestações culturais tradicionais e populares, além de relações sociais ameaçadas pela modernidade da época. Para o autor citado acima, o romance de trinta é uma "máquina de rememoração" e "é na memória que juntam fragmentos de história, lembranças pessoais, de catástrofes, de fatos épicos que desenham o rosto da região [...]região da permanência, do ritmo lento, da sedimentação cultural, da família, afetiva e infantil".

A lembrança íntima do indivíduo sempre se mistura com o passado dos grupos com que ele se relaciona ou se relacionou ao longo de sua vida. As histórias individuais fazem parte da memória da sociedade, por meio da qual ela constrói sua identidade cultural.

José Lins do Rego publica em 1932 seu primeiro romance intitulado Menino de Engenho. O autor empresta suas memórias ao protagonista Carlos de Melo, trata-se de uma obra autobiográfica. Sua prosa recria a sociedade de sua infância sem um olhar crítico, mas meramente nostálgico e subjetivo. "A infância e o engenho surgem como presenças vivas, sempre atuais a oporem-se constantemente à realidade nova" (Albuquerque, 2011). Acontecimentos marcantes em um determinado período de sua vida, entre os quatro e os doze anos de idade, são registrados no romance, como a morte de sua mãe, a chegada ao engenho do avô, o contato com outros mundos (dos escravos livres), seu primeiro amor, suas primeiras experiências sexuais, a cultura do engenho dentre outros. Desliza seu carretel de lembranças tecendo com as teias da memória sua narrativa.

Seu primeiro romance foi um marco da literatura brasileira e alvo de muitas críticas.

\section{Literatura e Cultura}


É do contexto local que nasce o referencial cultural que marcará o sujeito na sua individualidade e permitirá que ele alargue suas fronteiras culturais. Para Canclini (2003), ter uma identidade é antes pertencer a uma entidade em que tudo o que é compartilhado pelos que habitam esse lugar se torne idêntico ou intercambiável.

Ao conceito de cultura são atribuídas várias definições. Santaella (2000) aponta que

todos os campos das humanidades, da filosofia às ciências sociais, da filologia à antropologia, e esta especialmente, possuem definições específicas de cultura, adaptadas e adequadas à delimitação das fronteiras do conhecimento que cada um desses campos recobre.

Albuquerque (2011) ressalta que, no Brasil, os discursos regionalistas surgiam "à medida que se dava a construção da nação e que a centralização política do Império ia conseguindo se impor sobre a dispersão anterior", mas este regionalismo era a germinação do separatismo que culmina na busca de mudanças na década de vinte. Essas mudanças eram necessárias, já que a dimensão geográfica natural do espaço se tornava uma dimensão histórica, artificial, construída pelo homem. $O$ intelectual regionalista via o regional como uma vitrine de elementos culturais raros, destacados como relíquias às vias de extinção diante do progresso. Este intelectual "toma elementos do folclore e da cultura popular, notadamente rural, abordando-os com indisfarçável postura de superioridade".

Através da representação literária é possível conhecer elementos da cultura não apenas no que diz respeito às suas manifestações festivas, expressões folclóricas e outros costumes, mas também sobre a organização social, política e econômica da região.

Em Menino de Engenho, o regionalismo de Jose Lins do Rego aflora. O autor apresenta seu espaço social e geográfico e compartilha com o leitor a tradição cultural nordestina com seu folclore. Expõe costumes, crendices e superstições. 


\title{
3. Literatura e Cinema
}

Uma curiosidade a princípio, o cinema acabou tornando-se um recurso para os operários cansados esquecerem suas longas jornadas de trabalho mal pago.

Marcondes (1993) afirma que o cinema, nascido de uma pesquisa científica, pela primeira vez na história proporcionou a ilusão do movimento. Essa nova técnica possibilitava representar a vida sem necessidade da presença da pessoa, para ele, "a imagem é uma ponte de ligação entre o homem e seu imaginário." Esse imaginário é uma dimensão paralela ao mundo real do sujeito. A realidade é o cotidiano, com sua rotina, embates, luta pela sobrevivência; alegrias, tristezas, frustrações e realizações. O imaginário conflita com o real, pois anseia por renovação. Quando se lê um livro se é acometido pela surpresa das revelações nas histórias emocionantes, abrem-se brechas para a fantasia do leitor. Para o autor citado, a comunicação produzida industrialmente para as grandes massas tem, eventualmente, a função de captar suas fantasias, seus sonhos, seus desejos e domesticá-los. Lima citado em Mota (1999, p. ) diz que

\begin{abstract}
O cinema é uma arte extremamente popular, ele tem um lado apolíneo que tanto atrai as pessoas, aquela coisa que você idealiza o mundo e você pode de alguma maneira, formular questões através de exemplos e de moralidades, mas tem um lado dionisíaco que, ao mesmo tempo, é o lado mais forte do cinema. [...] $\mathrm{Na}$ verdade, tudo que as pessoas que entram numa sala de cinema querem é se divertir de alguma forma, elas entram ali para saírem do mundo de onde vieram, elas deixam a rua cheia de carros, entram na sala e, durante algum tempo, elas descontraem, elas ficam ali.
\end{abstract}

Na visão de Martino (2005) o cinema é um exemplo de primeira representação cultural em um nível de complexidade jamais imaginado pela história. "Pela primeira vez, o homem foi capaz de reproduzir seu cotidiano com alto grau de fidelidade". A produção em massa é a cultura do capital. A noção de cultura ganha novas dimensões com a chegada do cinema. 
Charles Pathé citado em Barbáchano (1979) ressalta que a burguesia também foi incorporada nesse ambiente proletariado do cinema, fazendo com que seu crescimento acelerado e o lucro só perdessem para a indústria bélica.

\subsection{Literatura sob a ótica do Cinema Novo}

Movimento de resistência ao cinema comercial, o Cinema Novo questionava todo o cinema já feito no Brasil. O grupo, denominado cinemanovistas, se reunia para a troca de experiências e informações técnicas sobre cinema, escrever manifestos, discutir política, produção cultural e a conjuntura econômica e social do país.

Atribuíam extrema importância a um cinema no Brasil como manifestação autêntica de cultura nacional e propunham um cinema que tivesse como objeto a realidade brasileira e utilizasse, como método, analisar essa realidade do ponto de vista econômico, social e político e das massas populares.

De acordo com Mota (1999) para Glauber Rocha e Nelson Pereira dos Santos, a literatura da década de trinta era uma bandeira retomada pelo argumento de um cinema que trouxesse a conscientização política.

Em 1964, quando se inicia o Golpe Militar, o Brasil ampliava os seus laços de associação com o capitalismo internacional. O Cinema Novo pode sobreviver graças à repercussão internacional de algumas fitas.

Para Xavier (2003) os filmes produzidos logo após o golpe militar de 1964 expressam as visões de seus autores frente à nova conjuntura política[...] nestes filmes, o nacionalismo passa a explicitar-se no diálogo com a cultura popular e erudita, sendo exemplo os filmes mais comportados que dialogam com a tradição literária.

Paiva (2006) afirma que "a teledramaturgia, ao explorar os enredos nordestinos seduz a opinião pública, exibindo os 
matizes de uma culturalidade nordestina em suas dimensões épicas e afetivas, românticas e transgressivas". Essa temática, explorada a partir da adaptação da literatura, foi abordada no cinema e, dentre as obras adaptadas, está o romance Menino de Engenho do escritor memorialista José Lins do Rego (1932), que virou filme de Walter Lima Júnior, exibido no ano de 1965.

Glauber Rocha atribuía a primeira fase do Cinema Novo a partir do filme Rio 40 graus a Vidas Secas, e a segunda fase a partir de Deus e o Diabo na Terra do Sol até Menino de Engenho.

Como ressalta Albuquerque (2011),

o Cinema Novo se propõe, portanto, a ser uma retórica de conscientização, de estabelecimento do que era a realidade nacional, superando nossa alienação, descobrindo nosso inconsciente sob os recalques produzidos por séculos de dominação colonial.

Esse olhar deveria retratar as temáticas nacionais e populares, com realismo e de forma pedagógica, denunciando os nossos problemas estruturais. "Um cinema feito por intelectuais de classe média que teriam adotado a perspectiva de classe do operariado, que se colocavam ao lado das forças 'progressistas' contra as 'reacionárias'” Para o autor, uma dessas forças seriam os coronéis nordestinos, os quais encarnavam a "face mais exposta de nosso subdesenvolvimento e primitivismo." O país buscava a construção de uma nova face, desenvolvida e industrializada e o "Cinema Novo deveria se tornar um veículo de produção da cultura popular desalienada".

O cinema apropria-se das formas narrativas literárias e essa transposição de um trabalho literário para o cinema exige adequação às especificidades de cada linguagem.

Saraceni (1968) dizia que o Cinema Novo aproxima-se da melhor literatura brasileira numa tentativa de suprir suas próprias deficiências como tradição dramática e que, "precisávamos por para fora, jogar nas telas, as emoções que 
sentimos ao ler certos autores nacionais."

\section{Deslocamentos e Transposições}

A obra de José Lins do Rego, Menino de Engenho, de 1932, chega ao cinema brasileiro pelas mãos de Walter Lima Júnior, em 1965. A literatura empresta ao cinema seu sucesso e da mesma forma que o livro consagra um iniciante. O filme recebeu importantes premiações no Brasil e no exterior e foi sucesso de bilheteria em todo país. É considerado um clássicos da cinematografia brasileira.

Walter Lima Júnior "ao considerar incongruência entre as linguagens literária e cinematográfica, vista por alguns como um empecilho para a adaptação, deixa entrever sua primeira concepção acerca da obra de José Lins - uma narrativa popular - e da intenção do que seja o seu filme - um documentário poético" nos diz Mota (1999).

Cardoso e Torres (2014) comentam que Menino de engenho, embora pertencente à corrente estética do Cinema Novo, é um filme em que percebemos a utilização de elementos estilísticos que, muitas das vezes, são evitados por essa corrente. O cineasta se valeu de uma linguagem fílmica mais clássica, menos fragmentada. A crítica social é um elemento dosado, sem exagero, como no romance de José Lins do Rêgo. "Também não observamos um desejo de se romper totalmente com a linguagem clássica do cinema". Como no livro, "Menino de engenho é mais voltado para a representação da memória infantil acerca dos engenhos de cana-de-açúcar. As experiências marcantes da infância de Carlinhos no ambiente rural do Nordeste é que vão traçando o fio narrativo do filme."

Além da própria vida do garoto, Walter Lima júnior destaca a crise provocada na região com chegada das usinas e a falência dos engenhos.

Mattos (2000) expõe que ao contrário das intenções de José Lins do Rego que, só desejava produzir uma obra 
memorialista, o cineasta faz uma crítica à sociedade. Conforme o autor, "Walter pretendia fornecer um painel sobre a incompetência daquela sociedade para se modernizar, a inaptidão para transformar o velho em novo" pois, essa era "a visão dialética da realidade brasileira em permanente tensão entre o conservadorismo do modo agrário dos latifúndios e a necessidade de transformação industrializadora". Para o autor, este ponto de vista social equiparava Menino de Engenho ao discurso do Cinema Novo.

A adaptação deve ser vista como um diálogo não só com o texto de origem, mas com o próprio contexto que se pretende adaptara, defende Xavier (2003). A insistência na "fidelidade" que deriva das expectativas que o espectador traz ao filme, baseadas na sua própria leitura do original - é um falso problema porque ignora diferenças essenciais entre os dois meios, porque geralmente despreza a dinâmica dos campos de produção cultural nos quais os dois meios estão inseridos (Johnson, 2003).

Walter Lima Junior dizia que "livro é livro, filme é filme." Para ele, os dois formatos eram incompatíveis. O que interessava ao cineasta era "transmitir ao espectador o sentimento que o autor Ihe provocou" com liberdade para mudar a história, alterar ganchos narrativos, sem o compromisso de ser fiel ao autor. $O$ único compromisso com a fidelidade, seria restabelecer na tela a forma como o autor o atingiu (Mattos, 2000).

Para Plaza (2001) "numa tradução intersemiótica, os signos empregados têm tendência a formar novos objetos imediatos, novos sentidos e novas estruturas que, pela sua própria característica diferencial, tendem a se desvincular do original".

A adaptação literária não pode ser discutida como uma simples tradução textual para as telas de cinema.

Além de serem linguagens distintas, existe no texto apenas a presença da linguagem verbal para estruturar sua narrativa, enquanto no cinema tem-se a presença 
não só da linguagem verbal, como também da linguagem visual, sonora e musical (Novo, 2000).

Conforme o autor citado, "além do distanciamento entre linguagens, o filme e sua obra original distanciam-se também através do tempo". Essa distância proporciona novas percepções diante do tema retratado porque envolve também o contexto tanto do livro quanto do filme.

Em uma breve análise da tradução intersemótica de Menino de Engenho, observa-se pequenas intervenções que se ajustam à ótica do Cinema Novo. A essas intervenções denominamos deslocamentos (pequena modificação em comparação com obra literária) e transposições (inserções feitas pelo cineasta que não constam no livro).

Dentre os deslocamentos, observa-se: quando a mãe do menino é assassinada, ao contrário do livro, ele foge angustiado ao ver o corpo; o Carlinhos do filme é mais introspectivo e melancólico que o do livro; a narração em primeira pessoa de José Lins do Rego é substituída pela construção do ponto de vista do menino e percebe-se que o personagem de Antônio Pitanga encarna os contadores de história de assombração e representa uma mistura de tipos pitorescos narrados no livro.

Dentre as transposições, temos a visita do usineiro ao engenho Santa Rosa; A conversa da tia Maria e prima Maria Lúcia na sala de estar, que falam sobre relacionamento conjugal, moda e música e o gramofone; o beijo entre tio Juca e a prima Maria Lucia e o seguinte diálogo do tio Juca com a prima: "há muito por fazer na propriedade, por gente moça com ideias novas, que tem disposição de transformar esse engenho de banguê num mundo de máquinas" e a última cena do filme, onde Carlinhos entra no trem com o tio Juca, com destino ao colégio e observam um automóvel que cruza a linha férrea com certa velocidade.

\section{Considerações Finais}


José Lins do Rego resumiu sua obra literária em uma sondagem da alma do povo, nas fontes do folclore, um regionalismo orgânico, revelador do caráter brasileiro, formador de um povo que não seria uma massa uniforme e sem cor. Seu trabalho adaptado para a produção cinematográfica é influenciado pelo Cinema Novo e transpassado pela perspectiva de Walter Lima Junior.

Por meio da mídia cinematográfica, Walter Lima Junior se apropria da proposta de um Cinema Novo e faz da literatura de José Lins do Rego um cinema brasileiro, com manifestações nacionais, retratando assim a realidade do país.

Essa breve análise da tradução intersemiótica da Literatura para o Cinema, permitiu avaliar o diálogo entre cinema e literatura a partir da obra Menino de engenho, do ponto de vista dos deslocamentos e transposições sob a ótica do Cinema Novo.

A versão do romance para a linguagem fílmica não tem a pretensão de ser igual, melhor ou pior que a literatura. A obra cinematográfica é livre para fazer a sua releitura da história, contextualizá-la e, se convier, mudar o final. A literatura e o cinema são artes distintas, cada qual com sua intencionalidade e seu público alvo. Apesar disso, essas artes podem (e devem) se relacionar numa perspectiva dialógica.

\section{Referências}

Albuquerque Jr. (2011). A invenção do nordeste e outras artes. São Paulo : Cortez,.

Barbáchano, C. (1979). O cinema, arte e indústria. São Paulo: Salvat do Brasil.

Canclini, N. (2003) Culturas Híbridas: estratégias para entrar e sair da modernidade. ( Ana Regina Lessa \& Heloísa Pezza Cintrão, trad.). São Paulo: Edusp.

Cardoso, D. \& Torres, A. (2014). Um engenho de memórias: o processo de tradução de menino de engenho para o cinema. [versão eletrônica] Revista Universitária do Audiovisual. Recuperado em 10 
outubro, 2014 de http://www.rua.ufscar.br/um-engenho-de-memoriaso-processo-de-traducao-de-menino-de-engenho-para-o-cinema/

Johnson, R. (2003). Literatura e cinema, diálogo e recriação: o caso de Vidas Secas. Literatura, cinema e televisão. São Paulo: Editora Senac.

Marcondes Filho, C. (1998). Televisão: a vida pelo vídeo. 11. ed. São Paulo: Moderna.

Mattos, C. (2002). Walter Lima Júnior: viver cinema. Rio de Janeiro: Casa da Palavra.

Martino, L. (2005). Comunicação: troca cultural? São paulo: Paulus.

Mcluhan, M. (1969). A Galáxia de Gutenberg : a formação do homem tipográfico. São Paulo : Ed. da Univ.

Walter L. Jr. (1965). Menino de engenho [Filme-vídeo]. Walter Lima Júnior et. al. Prod., Walter L. Jr. dir. Mapa Filmes. João Pessoa: Mapa. 1 bobina cinematográfica, 116min. preto. son.

Mota, A. (1999). O primeiro filme de um cineasta: menino de engenho, de Walter Lima Júnior. Dissertação, Unversidade Federal do Rio de Janeiro, Rio de Janeiro, Brasil.

Paiva, C. (2011). Imagens do Nordeste brasileiro na idade mídia: elementos para uma antropológica da ficção audiovisual. Recuperado em 10 julho, 2011 de: http://www.bocc.ubi.pt/pag/paiva-claudiocardoso-imagens-nordeste-brasileiro.pdf.

Plaza, J. (2001). Tradução intersemiótica. São Paulo: Perspectiva.

Rego, J. L. (1932). Menino de engenho. Rio de Janeiro: José Olímpio. Novo, R. (2011). Adaptações literárias e o cinema de autor no Cinema Novo. Recuperado em 10 julho, 2011 de http://www.ufscar.br/rua/site/?p=2260.

Santaella, L.(2000). Cultura das mídias. São Paulo : Experimento.

Saraceni, P. (1968). Conversa com Saraceni. Diário de Notícias, 1968. p. 2, seção 2 .

Silva, V. (2005). Teoria da Literatura. Porto: A Medina.

Xavier, I. (2003). Do texto ao filme: a trama, a cena e a construção do olhar no cinema. Literatura, cinema e televisão. São Paulo: Editora SENAC. 